\title{
Unusual behavior of gem-diamino peptides in fast atom bombardment and electrospray ionization mass spectrometry
}

\author{
B. Vivet, F. Cavelier, C. Enjalbal, J. Martinez, P. Sanchez and J.-L. Aubagnac*
}

Laboratoire des Aminoacides, Peptides et Protéines, UMR 5810, Université Montpellier II, 34095 Montpellier Cedex 05, France

* Corresponding author: aubagnac@univ-montp2.fr

\begin{abstract}
Gem-diamino peptides were studied by fast atom bombardment (FAB) and electrospray ionization (ESI) mass spectrometry to evidence specific fragmentations involving the labile modified bonds. Base peaks recorded in the positive mode were attributed to fragment ions even with soft atmospheric pressure ionization. The criterion that one ion corresponds to one molecule in ESI mass spectra commonly encountered in high throughput analysis of combinatorial libraries must be considered with caution when fragile structures are analyzed.
\end{abstract}

\section{Abbreviation}

EB: Electrostatic then magnetic sectors

ESI: Electrospray ionization
FAB: Fast atom bombardment

FIA: Flow injection analysis

G: Glycerol

Gem: Geminal

MALDI: Matrix assisted laser desorption ionization

NBA: $m$-nitrobenzylalcohol

\section{Introduction}

Backbone modified peptides are commonly investigated in the frame of therapeutic chemistry because of their increased stability towards enzymatic degradation. For these pseudopeptides, the standard analytical procedures using amino acid analysis and Edman degradation, which require proteinogenic residues, fail to provide structural identification. In contrast, mass spectrometry is particularly well suited for their characterization since informative spectra have been recorded for a vast variety of biomolecules using 
soft ionization techniques such as FAB [1], ESI [2] and MALDI [3].

Characterization of peptides containing a gem-diamino moiety has been reported in the literature using FAB mass spectrometry in the positive mode [4,5]. The modified bonds were found to be more labile than the native amide linkages under the FAB bombardment providing extensive fragmentations. The fact that the protonated molecular ion was not the base peak in the various recorded spectra especially when the gem-diamino group was in the C-terminal position [5] indicated that difficulties could be expected for the identification of unknown structures.

Thus, the softer and more sensitive ESI technique which should reduce backbone ruptures was investigated for unambiguous gem-diamino peptides characterization. Indeed, very little fragmentation is induced for low molecular weight molecules by using an appropriately chosen cone voltage, and thus each recorded ion in the ESI spectrum is related to one compound. Under such conditions, analysis of mixtures could be done by simple inspection of flow injection analysis (FIA) spectra without requiring chromatographic separation. There, the behavior of gem-diamino peptides was simultaneously studied by FAB and ESI mass spectrometry.

\section{Experimental}

\section{Synthesis}

Synthesis of the compounds are described elsewhere [6]. Abbreviations used throughout this paper are in accordance with the IUPAC nomenclature. In addition: pGlu = pyroglutamic acid, $g$ Leu $=$ gem-diamino leucine .

\section{Mass spectrometry}

ESI mass spectra were recorded on a Platform II quadrupole mass spectrometer (Micromass, Manchester, UK) fitted with an electrospray ion source. The mass spectrometer was calibrated in the positive ion mode using a mixture of $\mathrm{NaI}$ and CsI. Data were acquired in the scan mode from $\mathrm{m} / \mathrm{z} 200$ to $\mathrm{m} / \mathrm{z} 2000$ in $4 \mathrm{~s}$. Fifteen scans were summed to produce the final spectrum. Samples were dissolved in the mixture $\mathrm{H}_{2} \mathrm{O} / \mathrm{CH}_{3} \mathrm{CN} / \mathrm{HCOOH}(49: 49: 2$, v/v) and infused into the ESI source at a flow rate of $50 \mu \mathrm{l} / \mathrm{min}$. Voltages were set at $+3.5 \mathrm{kV}$ for the capillary and adjusted for the sampling cone. The source was heated at $120^{\circ} \mathrm{C}$.

FAB mass spectra were recorded on a Jeol JMS DX300 (Jeol Ltd, Tokyo, Japan). This instrument is of EB design. The energy of the neutral atom beam was $3 \mathrm{KeV}$ (emission current $20 \mathrm{~mA}$ ). Calibration was accomplished using Ultramark 1621 (Heraus, Karlsruhe, Germany) as a reference. FAB mass spectra were measured at a resolution of 1000. Xenon was used as the collision gas at a pressure to reduce the beam of the parent ion by $30 \%$. The collision cell was located in the field-free region before the electric sector. The collision energy was $3 \mathrm{KeV}$. The resulting fragment ions were analyzed by a B/E linked scan method. Data were acquired and processed with a HP Apollo series using the Jeol complement software. Glycerol and meta-nitrobenzylalcohol (Aldrich) was used as the matrix. Solutions of the modified peptides in methanol were mixed with a drop of glycerol or m-nitrobenzylalcohol directly on the target.

\section{Results and discussion}

As part of our on-going neurotensin program [6], we have been interested in the following gem-diamino peptide, pGluLeu-Tyr-Glu-Asn-Lys-Pro-Arg-Arg-Pro-Tyr-Ile-gLeu (1).

Product purity was checked by HPLC. The subsequent ESI mass spectrometric analysis in the positive mode produced a spectrum containing ions with unexpected high abundances (Fig. 1). The protonated molecular ion $[\mathrm{M}+\mathrm{H}]^{+}$ at $\mathrm{m} / \mathrm{z} 1643$ and the doubly charged species $[\mathrm{M}+2 \mathrm{H}]^{2+}$ at $\mathrm{m} / \mathrm{z} 822$ indicated the presence of the target gem-diamino peptide but additional rather intense signals at $\mathrm{m} / \mathrm{z} 813,779$ and 757 were also recorded.

Surprisingly, the abundances of these unexpected ions were comparable to those of the product signals. Taking in account a potent hydrolysis of the gem-diamino moiety [7], side-products issued from breakdown of the modified peptide backbone in the acidic medium was first considered. The product stability was thus controlled by submitting the solution studied by ESI to a second HPLC analysis. A single peak at the same retention time before and after mass spectrometric experiments was observed. The absence of a chemical degradation in the ESI source was also confirmed by analyzing a freshly made solution of compound $\mathbf{1}$ in acetonitrile/water without any acid. The same mass spectrum was recorded in acidic and neutral media. Despite the soft ionization conditions, fragmentation is thus the sole explanation for such intense signals.

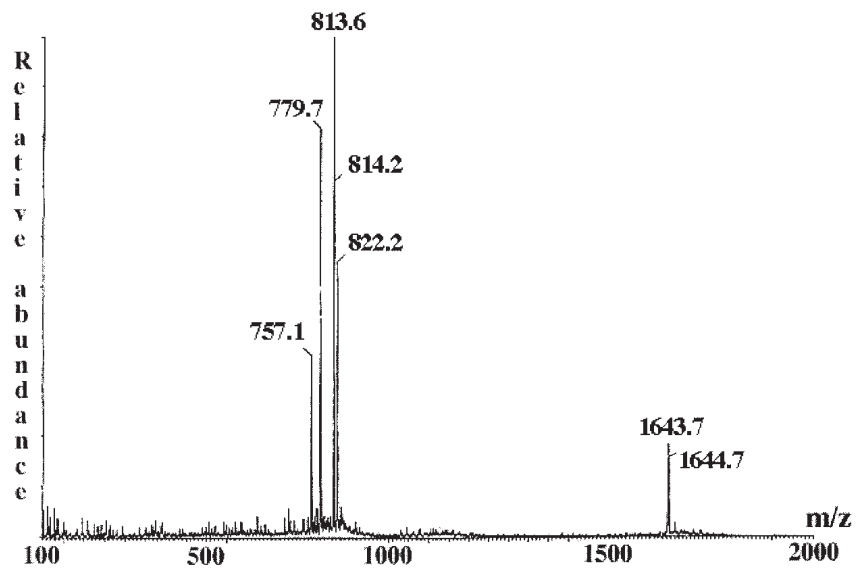

Figure 1. Positive electrospray ionization mass spectrum of peptide 1. 


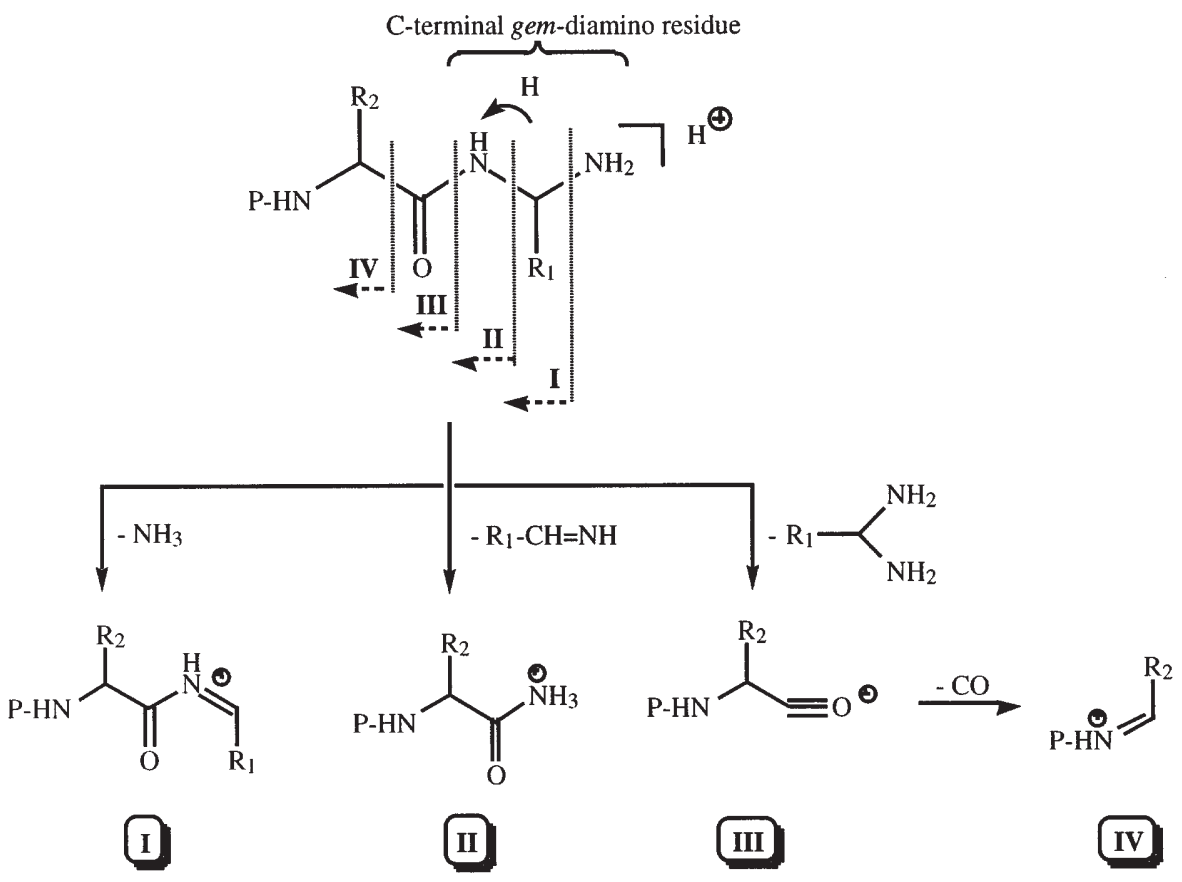

Scheme 1. Fragmentation pathways of C-terminal gem-diamino peptides.

The fact that the modified amide bonds were positioned at the C-terminus explained why so important fragmentations could be obtained (Scheme 1). Similarly to FAB mass spectrometry [4,5], loss of ammonia from the terminal amino group (pathway I) provided the most abundant ion whereas loss of the C-terminal imine (pathway II) and of the gemdiamino moiety (pathway III) were occurring to a less extent. These ruptures were solely observed for the doubly protonated ion at $\mathrm{m} / \mathrm{z} 822$. Indeed, the presence of highly basic residues in compound 1 implied that the first protonation should happen on the Lys-Pro-Arg-Arg-Pro sequence. The fixation of the second proton on one nitrogen of the gem-diamino group should be remote enough to avoid charge repulsion. Under such conditions, the fragmentation described in scheme 1 being directed by the charge on the C-terminal amino group, backbone breakdown could only be obtained from the $[\mathrm{M}+2 \mathrm{H}]^{2+}$ ion as observed in the recorded spectrum with the base signal corresponding to $\left[\mathrm{M}+2 \mathrm{H}-\mathrm{NH}_{3}\right]^{2+}$ at $\mathrm{m} / \mathrm{z} 813$.
In order to probe whether the previously observed fragmentations were common in C-terminal gem-diamino peptides, model sequences $\mathbf{2}$ to $\mathbf{5}$ listed in table I were synthesized and analyzed by FAB and ESI mass spectrometry. These modified dipeptide chains were designed with no other basic site than the gem-diamino moiety which made possible to follow fragmentations directly from the monoprotonated molecular ion.

The same fragmentation patterns depicted in scheme 1 corresponding to the respective loss of ammonia, of the Cterminal imine $\left(\mathrm{R}_{1}-\mathrm{CH}=\mathrm{NH}\right)$ and of the gem-diamino group $\left(\mathrm{R}_{1}-\mathrm{CH}-\left(\mathrm{NH}_{2}\right)_{2}\right)$ were observed for all compounds in both FAB and ESI experiments as detailed in table I. The major backbone rupture occurred by loss of ammonia with both ionization techniques whatever the experimental conditions.

As an illustration, FAB mass spectra of compound $\mathbf{3}$ recorded with m-nitrobenzyl alcohol (NBA) as matrix is

Table I. Observed ions in the positive FAB and ESI mass spectra of model sequences.

\begin{tabular}{|c|c|c|c|c|c|c|}
\hline \multirow[b]{2}{*}{ Studied sequences } & \multicolumn{2}{|c|}{ Precursor ion } & \multicolumn{4}{|c|}{ Detected fragment } \\
\hline & {$[\mathrm{M}+2 \mathrm{H}]^{2+}$} & {$[\mathrm{M}+\mathrm{H}]^{+}$} & $\mathbf{I}$ & II & III & IV \\
\hline 1 & 822 & & 813.6 & 779.7 & - & 757.1 \\
\hline Fmoc-Ile-gLeu (2) & & 438 & 421 & 353 & 336 & - \\
\hline Fmoc-Val-gAla (3) & & 382 & 365 & 339 & 322 & - \\
\hline Fmoc-lle-gPhe (4) & & 472 & 455 & 353 & 336 & - \\
\hline Fmoc-Phe-gVal (5) & & 458 & 441 & 387 & 370 & - \\
\hline
\end{tabular}




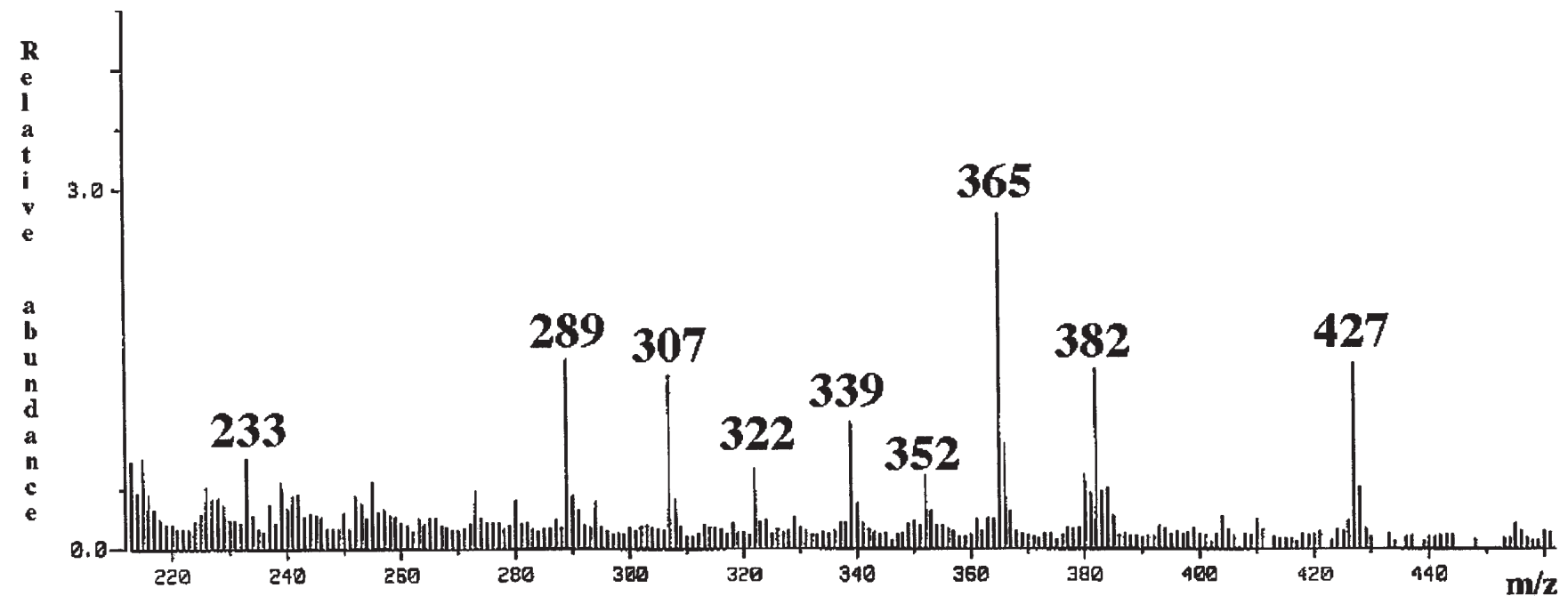

Figure 2. Fast atom bombardment mass spectrum of peptide Fmoc-Val-gAla 3 recorded with m-nitrobenzyl alcohol (NBA).

reproduced in figure 2 . In addition to matrix related ions such as $[2 \mathrm{NBA}+\mathrm{H}]^{+}$at $\mathrm{m} / \mathrm{z} 307$ and $\left[2 \mathrm{NBA}+\mathrm{H}-\mathrm{H}_{2} \mathrm{O}\right]^{+}$at $\mathrm{m} / \mathrm{z} 277$, the expected protonated molecular ion $[\mathrm{M}+\mathrm{H}]^{+}$at $\mathrm{m} / \mathrm{z} 382$ was detected together with the main fragment $\left[\mathrm{M}+\mathrm{H}-\mathrm{NH}_{3}\right]^{+}$at $\mathrm{m} / \mathrm{z} 365$. An adduct ion $\left[\mathrm{M}+\mathrm{H}+\mathrm{NO}_{2}\right]^{+}$at $\mathrm{m} / \mathrm{z} 427$ was also present.

In ESI experiments, various sampling cone voltages ranging from 10 to $100 \mathrm{~V}$ were applied to modulate the extent of fragmentation. Increasing the extraction potential between the ionization source and the analyzer provides collisions with enhanced energies, which could lead finally to bond cleavage [8]. Whatever the operating conditions, the gemdiamino peptides were found to behave as described in FAB mass spectrometry. For instance, the spectra of compound 2 recorded at $10 \mathrm{~V}$ and $80 \mathrm{~V}$ respectively are displayed in figures 3 and 4. Even at very low sampling cone voltage $(10 \mathrm{~V})$, the loss of ammonia was seen, indicating a very labile bond. Nevertheless, the abundance of the corresponding fragment ion at $\mathrm{m} / \mathrm{z} 421$ was increasing significantly

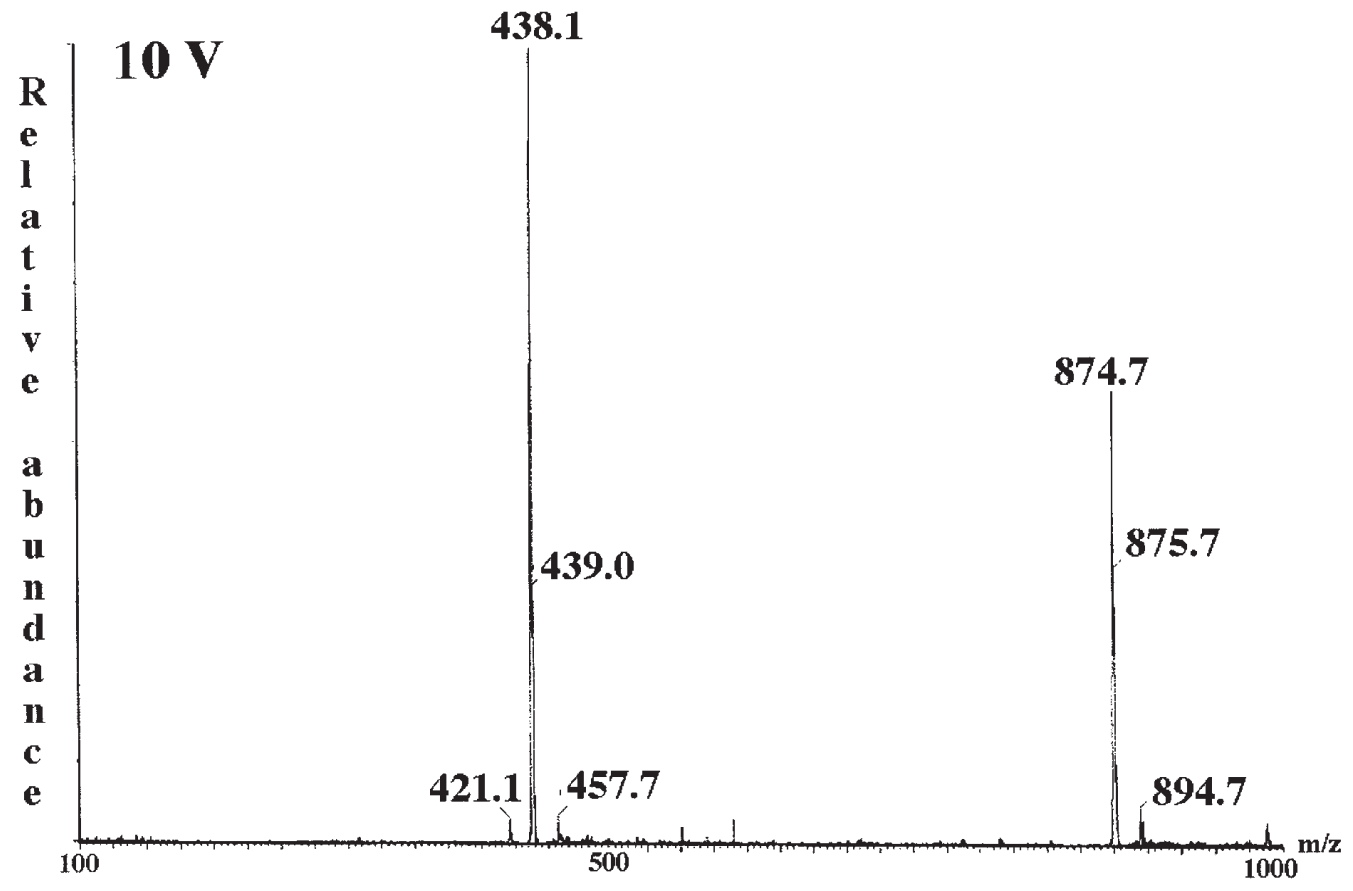

Figure 3. Electrospray ionization mass spectrum of peptide Fmoc-lle-gLeu 2 recorded at $10 \mathrm{~V}$. 


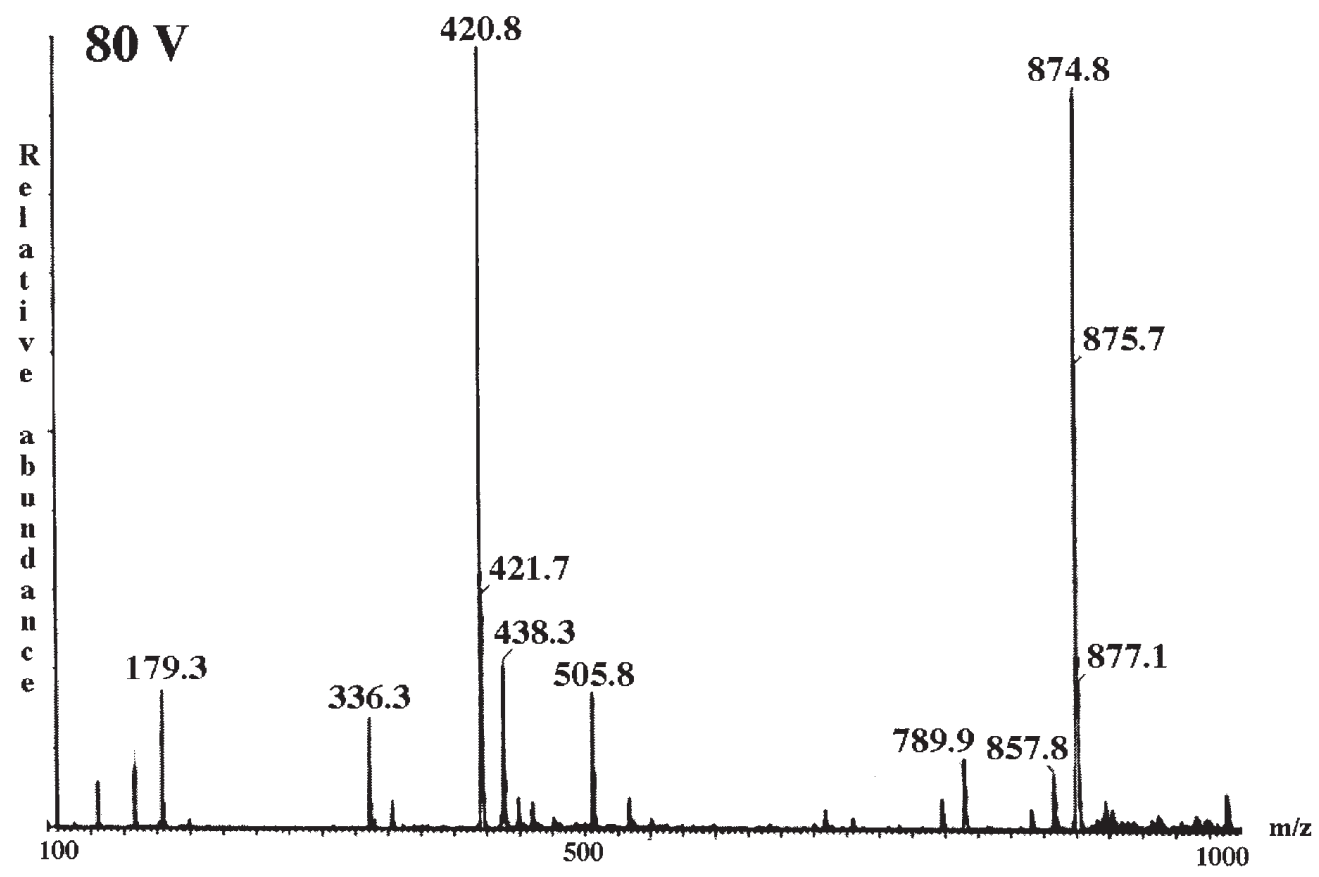

Figure 4: Electrospray ionization mass spectrum of peptide Fmoc-lle-gLeu 2 recorded at $80 \mathrm{~V}$.

from $10 \mathrm{~V}$ to $80 \mathrm{~V}$, being the base peak from $30 \mathrm{~V}$ on. It should also be noted that the dimer ion $[2 \mathrm{M}+\mathrm{H}]^{+}$at $\mathrm{m} / \mathrm{z} 875$ was exhibiting the same fragmentation producing $[\mathrm{M}+\mathrm{H}-$ $\left.\mathrm{NH}_{3}\right]^{+}, \quad\left[\mathrm{M}+\mathrm{H}-\mathrm{R}_{1}-\mathrm{CH}=\mathrm{NH}\right]^{+}, \quad\left[\mathrm{M}+\mathrm{H}-\mathrm{R}_{1}-\mathrm{CH}-\left(\mathrm{NH}_{2}\right)_{2}\right]^{+}$at $\mathrm{m} / \mathrm{z}$ 858, 790 and 773, respectively. These results which were observed for all studied compounds implied that abundant fragmentation could occur in ESI mass spectrometry although soft conditions with low sampling cone voltages were applied.

\section{Conclusion}

We have extended the fragmentation patterns of C-terminal gem-diamino peptides previously observed in FAB mass spectrometry to the softer ESI technique. Prompt loss of ammonia generated spectra where the expected protonated molecular ion was not the most abundant ion. This behavior which was encountered for all studied structures could lead to erroneous spectral interpretation if the criterion that atmospheric ionization methods provide solely $[\mathrm{M}+\mathrm{H}]^{+}$ion as base peak is applied, especially in the context of automated data processing required to profile parallel libraries in combinatorial chemistry [9].

\section{References}

1. Barber, M.; Bordoli, R. S.; Sedgwick, R. D.; Tyler, A. N. Nature 1981, 293, 270.

2. Fenn, J. B.; Mann, M., Meng, C. K.; Wong, S. F.; Whitehouse, C. M. Mass Spectrom. Rev. 1990, 9, 37.

3. Karas, M.; Bachmann, D.; Bahr, U.; Hillemkamp, F. Int. J. Mass Spectrom. Ion Proc. 1987, 78, 53.

4. De Angelis, F.; Ceccarelli, S.; Visconti, G. C.; Pinori, M.; Verdini, A. S. Biomed. Environm. Mass Spectrom. 1989, 18, 867.

5. Zhao, M.; Kleiman, H. K.; Mokotoff, M. J. Pept. Res. 1997, $49,240$.

6. Vivet, B. PhD Thesis.

7. Loudon, G. M.; Almond, M. R.; Jacob, J. N. J. Am. Chem. Soc. 1981, 103, 4508.

8. Siudzak, G. in Mass Spectrometry for Biotechnology; San Diego, CA: Academic Press, 1996.

9. Dulery, B. D.; Verne-Mismer, J.; Wolf, E.; Kugel, C.; Van Hijfte, L. J. Chromatogr. B 1999, 725, 39. 